\title{
Tumor suppressor expression and genetic characterization of benign and malignant chondroid syringoma
}

\author{
Dawn L. Williams ${ }^{1}$, Randall J. Olsen ${ }^{1,}{ }^{2}$, Donna M. Coffey ${ }^{1}$, Heather L. Hendrickson ${ }^{1}$, Candice R. \\ Hamilton $^{1}$, Philip T. Cagle ${ }^{1}$ \\ 1. Department of Pathology and Genomic Medicine, Houston Methodist Hospital, Houston, Texas, United States. 2. Center \\ for Molecular and Translational Human Infectious Diseases Research, Houston Methodist Research Institute, Houston, \\ Texas, United States.
}

Correspondence: Randall J. Olsen. Address: Houston Methodist Hospital, Houston, Texas, United States. E-mail: rjolsen@houstonmethodist.org

Received: J une 12, 2014

DOI : $10.5430 / \mathrm{crcp} . \mathrm{v} 2 \mathrm{n} 1 \mathrm{p} 28$
Online Published: September 17, 2014

\section{Abstract}

Chondroid syringoma is an uncommon epithelial and mesenchymal neoplasm of eccrine sweat glands. Most are benign, but some may exhibit aggressive behavior, including local recurrence and lymph node or distant metastases. Treatment is generally limited to radical surgical excision and possibly chemoradiation, although the latter is generally considered ineffective against these tumors. Histologic features of benign and malignant chondroid syringoma are similar, thus making morphology an unreliable marker for clinically aggressive behavior. Identification of biomarkers that predict clinical behavior would be potentially useful for selecting patients with malignant chondroid syringoma for targeted therapy. The purpose of this study was to investigate somatic mutations commonly involved in tumor pathways, and to determine if there is altered expression of tumor suppressors p16 and p53 in metastatic malignant versus benign chondroid syringoma. Five chondroid syringoma tissue samples were analyzed - 2 aggressive and 3 benign. Immunostaining for tumor suppressor genes p16 and p53 was performed. Genomic DNA was isolated and genetic analysis was performed using a custom Sequenom MassArray. Chondroid syringomas with clinically aggressive behavior showed strong nuclear p16 expression in contrast to those with benign behavior. Both the malignant and benign chondroid syringomas demonstrated positive p53 expression with varying intensity. No somatic mutations were identified in any of the chondroid syringomas.

\section{Key words}

p16, p53, Epithelial neoplasm

\section{I ntroduction}

Chondroid syringomas are uncommon benign neoplasms with epithelial and mesenchymal differentiation. They arise from the eccrine sweat glands, typically in the head and neck, but also in other sites, and account for $<0.01 \%$ of all primary skin tumors. Malignant chondroid syringoma is very rare, with only 43 cases reported in the literature ${ }^{[1]}$, and these are most often seen in the limbs. The histologic features of benign and malignant chondroid syringoma are similar, making 
morphology an unreliable predictor of malignancy. Most previously reported malignant chondroid syringomas were diagnosed by examination of metastases that typically involved lymph nodes, lung, or both ${ }^{[2]}$. Treatment is generally limited to radical surgical excision and possibly chemoradiation, although the latter is generally considered ineffective against these tumors ${ }^{[3]}$.

Molecular studies of chondroid syringoma have not been previously performed, and differences in tumor suppressor expression or genetic differences between malignant and benign tumors have not been elucidated. Since morphology is not a reliable method of predicting chondroid syringomas that are likely to exhibit clinically aggressive behavior, identification of biomarkers that predict clinical behavior would be valuable. Also, identification of predictive biomarkers could potentially be useful for selecting patients with malignant chondroid syringoma for targeted therapy as an alternative to surgery and chemoradiation.

Molecular abnormalities that may be significant in carcinogenesis include expression of tumor suppressor genes, such as p16 and p53, and oncogenes. Alternatively, genetic mutations resulting in the aberrant activation of oncogenes increase the probability that a normal cell will develop into a tumor cell. Somatic mutation profiling can identify mutations in signaling pathways and has potential targeted therapeutic applications. For example, identification of epidermal growth factor receptor (EGFR) mutations in lung cancer qualifies patients for therapy with highly effective tyrosine kinase inhibitors ${ }^{[4]}$. Our Molecular Diagnostics Laboratory has designed a custom multiplex gene mutation assay that can identify more than 150 mutations in the 21 genes most commonly implicated in various types of cancer.

The purpose of this study was two-fold: (1) to determine if there are alterations in the immunohistochemical expression of tumor suppressors p16 and p53 in metastatic malignant and benign chondroid syringomas, and (2) to investigate somatic mutations commonly involved in tumor pathways using the custom multiplex gene mutation assay.

\section{Material and methods}

A total of five formalin-fixed, paraffin-embedded chondroid syringoma specimens were collected from the tissue bank of the Department of Pathology and Genomic Medicine of the Houston Methodist Hospital in Houston, Texas, over a three year period (2009-2012). We identified three cases of benign chondroid syringoma, one case of metastatic malignant chondroid syringoma, and a case of recurrent chondroid syringoma from the same patient with the metastatic malignant chondroid syringoma. Demographic and clinical information were obtained from the electronic medical record (see the table). The study was approved by the Houston Methodist Research Institute Institutional Review Board (Pro00010728).

Table. p16, p53, and gene mutation panel results of chondroid syringomas

\begin{tabular}{|c|c|c|c|c|c|c|c|}
\hline Case No. & Age & Gender & Tumor Location & Diagnosis & $\begin{array}{l}\text { Gene Mutation } \\
\text { Panel }\end{array}$ & $\begin{array}{l}\text { p16 Tumor } \\
\text { Suppressor }\end{array}$ & $\begin{array}{l}\text { p53 Tumor } \\
\text { Suppressor }\end{array}$ \\
\hline 1 & 53 & $\mathrm{~F}$ & Right foot & $\begin{array}{l}\text { Benign chondroid } \\
\text { syringoma }\end{array}$ & Wild Type & Negative & Strong positive \\
\hline 2 & 62 & M & Right foot & $\begin{array}{l}\text { Benign chondroid } \\
\text { syringoma }\end{array}$ & Wild Type & Negative $^{\S}$ & Strong positive $\mathrm{e}^{\ddagger}$ \\
\hline 3 & 53 & M & Forehead/temple & $\begin{array}{l}\text { Benign chondroid } \\
\text { syringoma }\end{array}$ & Wild Type & Negative $^{\S}$ & Strong positive \\
\hline 4 & 84 & M & Lung $^{\#}$ & $\begin{array}{l}\text { Metastatic malignant } \\
\text { chondroid syringoma }\end{array}$ & Wild Type & Positive $^{\dagger}$ & Strong positive $\mathrm{e}^{\ddagger}$ \\
\hline 5 & 85 & M & Left posterior thigh ${ }^{*}$ & $\begin{array}{l}\text { Malignant hyaline } \\
\text { cell-rich chondroid } \\
\text { syringoma }^{*}\end{array}$ & Wild Type & Positive $^{\dagger}$ & Weak positive \\
\hline
\end{tabular}

${ }^{\#}$ : index case; ${ }^{*}$ : recurrent lesion in index case; ${ }^{\S}$ : ductal structures with rare, focal nuclear staining $(<5 \%){ }^{\dagger}$ and $^{\ddagger}$ : strong nuclear staining 
Histologic sections with characteristic microscopic features of syringoma were confirmed by two pathologists. Areas containing epithelial and myoepithelial elements within a chondromyxoid stroma and areas with hyaline cell change in the index metastatic malignant case were identified for macrodissection. Genomic DNA was isolated from $10 \mu \mathrm{m}$ sections of formalin-fixed, paraffin-embedded tumor samples using DNeasy Blood and Tissue Kit (Qiagen, Valencia, CA, USA) according to the manufacturer's instructions. Molecular analysis of the five tumors was performed using a custom assay as previously described ${ }^{[5]}$. The genotype panel detects mutations in the 21 genes most commonly implicated in cancer, including ABL1, AKT1, AKT2, BRAF, CDK4, EGFR (including exons 18, 19, 20 and 21), ERBB2, FGFR1, FGFR3, FLT3, HRAS, IDH1 (codon 132), IDH2 (codons 140 and 172), JAK2, KIT, KRAS, MET, NRAS, PDGFA, PIK3CA and RET.

Additionally, the five chondroid syringoma cases were stained for p16 and p53. Sections (4 $\mu \mathrm{m})$ of paraffin-embedded tumor samples were consecutively cut and baked in an oven at $60^{\circ} \mathrm{C}$ for 20 min. Immunostaining for p16 and p53 was performed using the Ventana Ultra Benchmark Automatic staining platform (Ventana Medical Systems, Tuscon, AZ, USA). All associated solutions and antibodies were purchased from Ventana unless otherwise noted. The slides were automatically deparaffinized and rehydrated using an EZ Prep solution. Antigen retrieval was achieved with ULTRA CC1 solution for 24 min of incubation. Sections were then incubated in primary antibody for 20 min for both p16 (CINtec, clone E6H4) and p53 (clone DO-7). The Benchmark platform uses a polymer detection system called OptiView to stain the antigen site brown. The sections were counterstained using Hematoxylin for staining contrast. Slides were then removed from the automated system and dehydrated through graded alcohols, cleared in xylene, covered, and analyzed by light microscopy.

\section{Results}

Immunohistochemistry for p16 tumor suppressor (nuclear staining) expression was positive in ductal structures in both the metastatic malignant chondroid syringoma and the recurrent thigh lesion. While p16 staining in benign chondroid syringoma case 1 was negative, p16 staining in benign chondroid syringoma cases 2 and 3 showed less than 5\% focal nuclear staining in ductal structures; this staining pattern was interpreted as negative (see Figure 1, A-E).

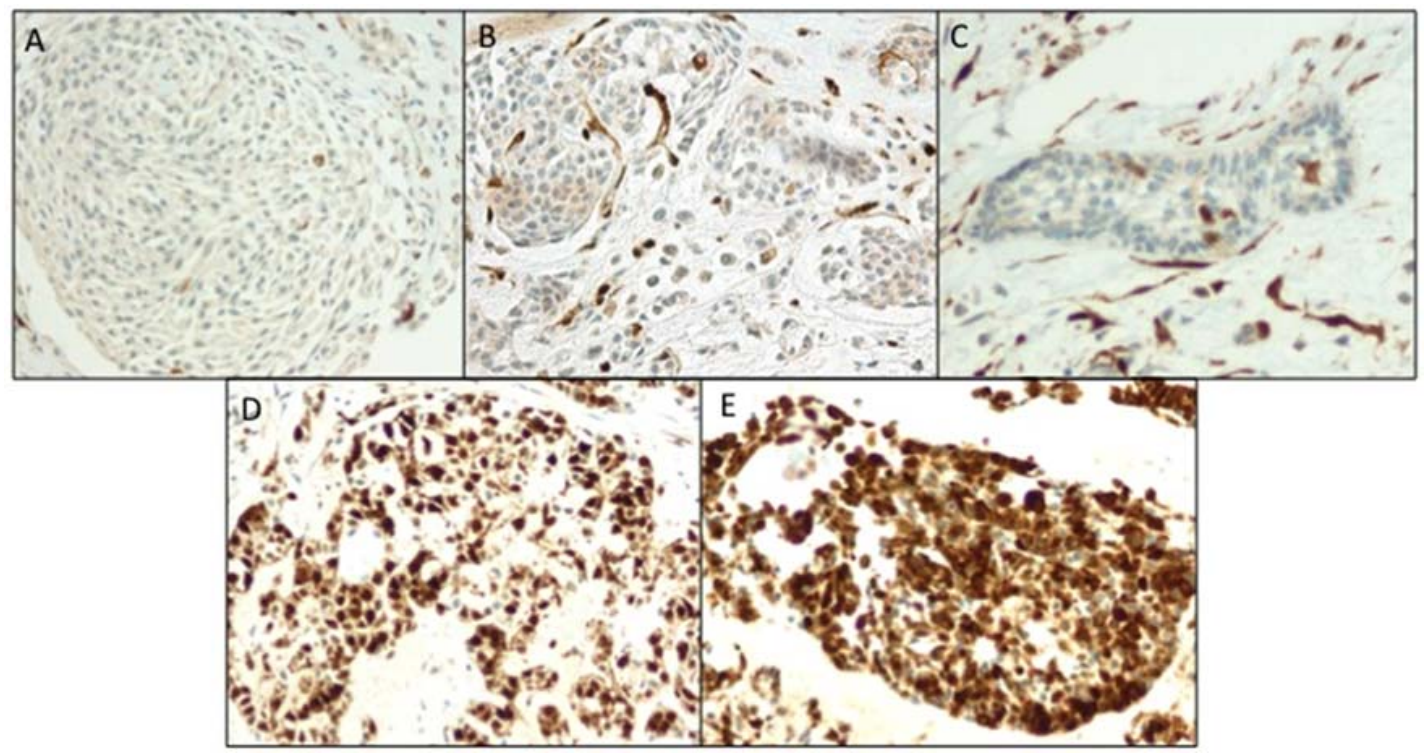

Figure 1. Immunohistochemistry for p16. (A) Negative p16 staining, benign chondroid syringoma, case 1. (B) Ductal structures with rare focal nuclear staining $(<5 \%$ ), benign chondroid syringoma, case 2. (C) Ductal structures with rare focal nuclear staining $(<5 \%$ ), benign chondroid syringoma, case 3. (D) Strongly positive nuclear staining in ductal structures, metastatic malignant chondroid syringoma, case 4. (E) Strongly positive nuclear staining in ductal structures, recurrent thigh lesion, case 5. Magnification, 20× 
Nuclear staining for p53 tumor suppressor expression was strongly positive in ductal structures in the three benign chondroid syringomas (cases 1, 2, and 3) and the metastatic malignant chondroid syringoma (case 4). p53 staining was also positive in ductal structures in the recurrent thigh lesion (case 5); however it was weakly positive, as compared to the strong positivity observed in the other cases (see Figure 2, A-E).

The gene mutation panel detected only wild-type alleles in the 21 genes assayed in all five chondroid syringoma tumor samples. That is, no somatic mutations or mutant alleles were detected in either the benign or malignant cases (see the table).

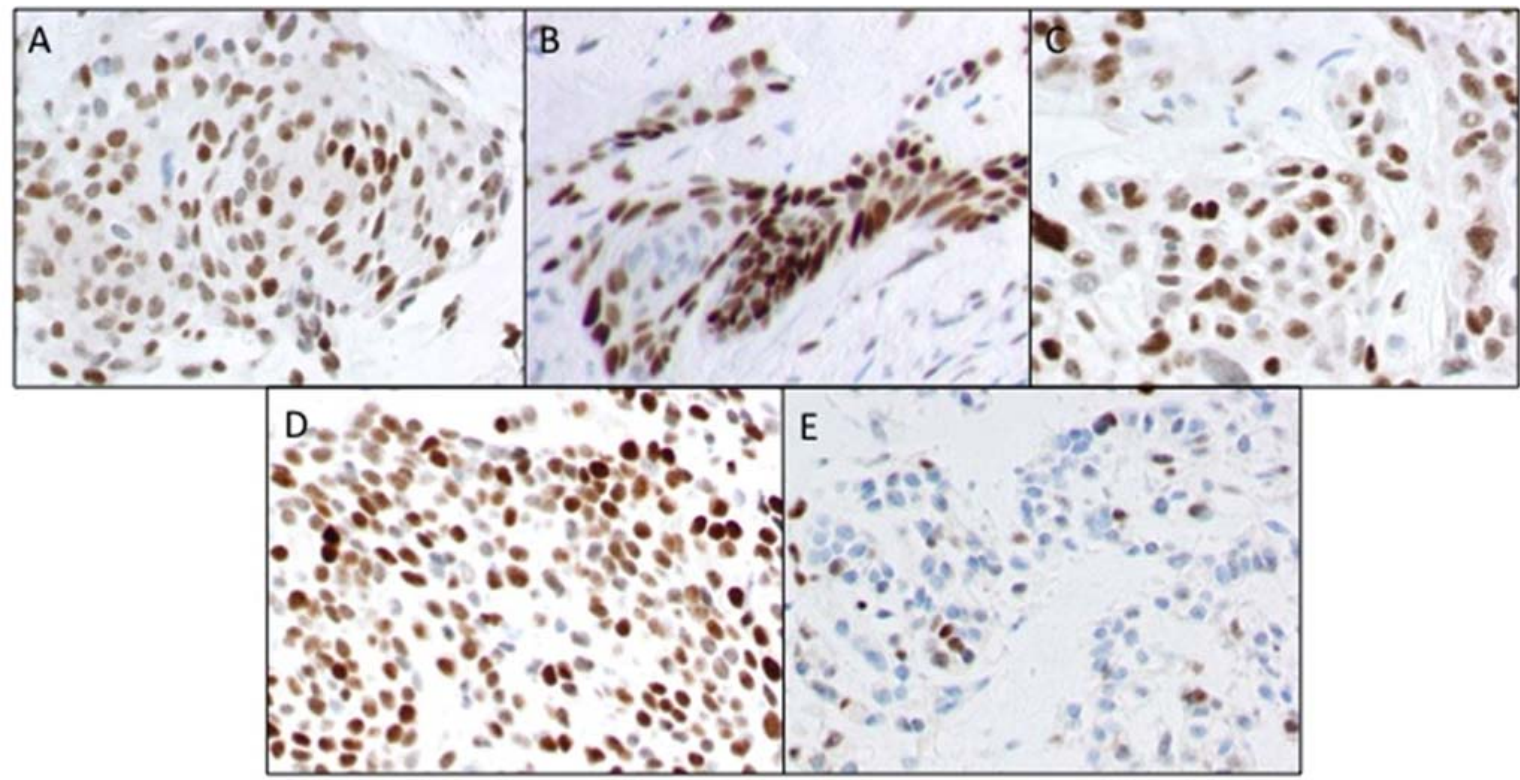

Figure 2. Immunohistochemistry for p53. (A) Strongly positive nuclear staining in ductal structures, benign chondroid syringoma, case 1. (B) Strongly positive nuclear staining in ductal structures, benign chondroid syringoma, case 2. (C) Strongly positive nuclear staining in ductal structures, benign chondroid syringoma, case 3. (D) Strongly positive nuclear staining in ductal structures, metastatic malignant chondroid syringoma, case 4. (E) Weakly positive nuclear staining in ductal structures, recurrent thigh lesion, case 5. Magnification, 40×

\section{Discussion}

The tumor suppressors p16 and p53 regulate, or slow down, cell division. When tumor suppressor genes are mutated or inactivated, cells have unregulated proliferation and this inactivation can result in tumorigenesis and cancer. p16 is commonly deleted or mutationally inactivated in cancer cells ${ }^{[6]}$; its inactivation is a common event in nearly half of all human carcinomas ${ }^{[7]}$. Normal proliferating cells do not express significant levels of p16 prior to multiple rounds of cell division ${ }^{[8]}$. Activation of p16 expression can be triggered by DNA damage, oncogenic stress, or physiological aging ${ }^{[9]}$. The significance of p16 overexpression is not fully understood, as it has been associated with both better and poorer cancer outcomes ${ }^{[10]}$. Mutations in p53 lead to dysfunctional apoptosis and unregulated proliferation of cells. Mutation at the p53 locus occurs in many cancers and this mutation is more frequent than any other known tumor suppressor gene ${ }^{[11,12]}$.

We performed immunohistochemical staining for p16 and p53 on five cases of chondroid syringoma, including three cases of benign chondroid syringoma, one case of metastatic malignant chondroid syringoma, and one case of recurrent chondroid syringoma from the patient with the metastatic tumor. Importantly, positive nuclear staining of p16 was observed in both the metastatic malignant chondroid syringoma and the recurrent thigh lesion, but it was essentially negative in all three benign chondroid syringomas. Benign proliferating cells do not typically express significant levels of 
$\mathrm{p} 16^{[8]}$, and its expression is associated with oncogenesis ${ }^{[9]}$. Although the oncogenic significance of p16 overexpression is not fully understood ${ }^{[10]}$, the observed overexpression of p16 in the malignant chondroid syringoma and the recurrent thigh lesion strongly suggests a possible role in their malignant behavior. In comparison, positive nuclear staining of p53 was observed in both the benign and malignant tumors. However, staining intensity was considerably decreased in the recurrent thigh lesion, indicating that this tumor may have acquired additional gene alterations in the p53 pathway.

We also performed targeted gene mutation analysis on the five chondroid syringoma cases using a multiplex assay. Unexpectedly, no somatic mutations were identified in 21 genes included in our panel. The panel was designed to detect gene mutations most commonly identified in all cancer types, with an emphasis on actionable polymorphisms (i.e., gene alterations with a known diagnostic, prognostic, or therapeutic implication). Our finding suggests that chondroid syringomas, in general, are genetically unique tumors. Interestingly, the gene mutation panel was not able to identify genetic changes explaining the metastatic behavior of the malignant chondroid syringoma taken from the index patient.

\section{Conclusion}

Malignant chondroid syringoma is a rare lesion, with only 43 cases reported in the literature. Unlike the benign chondroid syringoma, the malignant counterpart has a predilection for the extremities and metastasizes ${ }^{[13-16]}$. The histologic features of benign and malignant chondroid syringoma are similar, thus making morphology an unreliable predictor of malignancy. Most previously reported malignant chondroid syringomas were diagnosed by examination of metastases ${ }^{[3]}$. Importantly, we discovered that p16 was positive in both the metastatic malignant chondroid syringoma and the recurrent thigh lesion, but was undetected in the benign chondroid syringomas. p53 was weakly positive in the recurrent thigh lesion and strongly positive in the remaining cases. No gene mutations in commonly altered pathways were identified. These data underscore the need to further investigate chondroid syringomas at a whole genome level to elucidate the underlying genetic program resulting in these lesions.

\section{Acknowledgment}

We thank Keith Newton and Jordan Roberts for technical assistance and Kathryn Stockbauer for editorial assistance.

\section{References}

[1] Watarai, A., Amoh, Y., Aki, R., Takasu, H., Katsuoka, K. Malignant chondroid syringoma: report of a case with lymph node metastasis 12 years after local excision. Dermatol Online J. 2011; 17(9): 5. PMid: 21971270.

[2] Kiely, J. L., Dunne, B., McCabe, M., McNicholas, W. T. Malignant chondroid syringoma presenting as multiple pulmonary nodules. Thorax. 1997; 52(4): 395-396. PMid: 9196529. http://dx.doi.org/10.1136/thx.52.4.395

[3] Tural, D., Selcukbiricik, F., Gunver, F., Karismaz, A., Serdengecti, S. Facial localization of malignant chondroid syringoma: a rare case report. Case Rep Oncol Med. 2013; 907980. http://dx.doi.org/10.1155/2013/907980

[4] Lindeman, N. I., Cagle, P. T., Beasley, M. B., Chitale, D. A., Dacic, S., Giaccone, G. Association for Molecular Pathology. Molecular testing guideline for selection of lung cancer patients for EGFR and ALK tyrosine kinase inhibitors: guideline from the College of American Pathologists, International Association for the Study of Lung Cancer, and Association for Molecular Pathology. J Mol Diagn. 2013; 15(4): 415-453. http://dx.doi.org/10.1016/j.jmoldx.2013.03.001

[5] McQuitty, E., Zhang, W., Hendrickson, H., Tio, F. O., Jagirdar, J., Olsen, R., et al. Lung adenocarcinoma biomarker incidence in Hispanic versus non-Hispanic white patients. Arch Pathol Lab Med. 2014; 138(3): 390-394. http://dx.doi.org/10.5858/arpa.2013-0225-OA

[6] Tarakji, B., Baroudi, K., Darwish, S., Sakka, S., Hanouneh, S. Immunohistochemical expression of p16 in pleomorphic salivary adenoma. Turk Patoloji Derg. 2013; 29(1): 36-40. http://dx.doi.org/10.5146/tjpath.2013.01145

[7] Rocco, J. W., Sidransky, D. p16(MTS-1/CDKN2/INK4a) in cancer progression. Exp Cell Res. 2011; 264(1): 42-55. http://dx.doi.org/10.1006/excr.2000.5149 
[8] Chae, S. W., Sohn, J. H., Kim, D. H., Choi, Y. J., Park, Y. L., Kim, K., et al. Overexpressions of Cyclin B1, cdc2, p16 and p53 in human breast cancer: the clinicopathologic correlations and prognostic implications. Yonsei Med J. 2011; 52(3): $445-453$. http://dx.doi.org/10.3349/ymj.2011.52.3.445

[9] Witkiewicz, A. K., Knudsen, K. E., Dicker, A. P., Knudsen, E. S. The meaning of p16 (ink4a) expression in tumors: functional significance, clinical associations and future developments. Cell Cycle. 2011; 10(15): 2497-2503. PMid: 21775818. http://dx.doi.org/10.4161/cc.10.15.16776

[10] Peurala, E., Koivunen, P., Haapasaari, K. M., Bloigu, R., Jukkola-Vuorinen, A. The prognostic significance and value of cyclin D1, CDK4 and p16 in human breast cancer. Breast Cancer Res. 2013; 15(1): R5. http://dx.doi.org/10.1186/bcr3376

[11] Muller, P. A., Vousden, K. H. Mutant p53 in cancer: new functions and therapeutic opportunities. Cancer Cell. 2014; 25(3): 304-317. http://dx.doi.org/10.1016/j.ccr.2014.01.021

[12] Szychot, E., Brodkiewicz, A., Peregud-Pogorzelski, J. Will therapies that target tumour suppressor genes be useful in cancer treatment? Adv Clin Exp Med. 2013; 22(6): 861-864. PMid: 24431316.

[13] Kilpatrick, S. E., Hitchcock, M. G., Kraus, M. D., Calonje, E., Fletcher, C. D. Mixed tumors and myoepitheliomas of soft tissue: a clinicopathologic study of 19 cases with a unifying concept. Am J Surg Pathol. 1997; 21(1): 13-22. PMid: 8990137. http://dx.doi.org/10.1097/00000478-199701000-00002

[14] Mentzel, T., Requena, L., Kaddu, S., Soares de Aleida, L. M., Sangueza, O. P., Kutzner, H. Cutaneous myoepithelial neoplasms: clinicopathologic and immunohistochemical study of 20 cases suggesting a continuous spectrum ranging from benign mixed tumor of the skin to cutaneous myoepithelioma and myoepithelial carcinoma. J Cutan Pathol. 2003; 30(5): 294-302. PMid: 12753168. http://dx.doi.org/10.1034/j.1600-0560.2003.00063.x

[15] Shashikala, P., Chandrashekhar, H. R., Sharma, S., Suresh, K. K. Malignant chondroid syringoma. Indian J Dermatol Venereol Leprol. 2004; 70(3): 175-176. PMid: 17642601.

[16] Trown, K., Heenan, P. J. Malignant mixed tumor of the skin (malignant chondroid syringoma). Pathology. 1994; 26(3): $237-243$. PMid: 7991276. http://dx.doi.org/10.1080/00313029400169571 